\title{
Permeability of flax fibre mats: numerical and theoretical prediction from 3D X-ray microtomography images
}

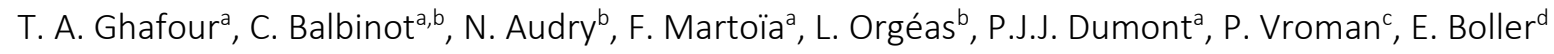 \\ aUniv . Lyon, INSA Lyon, CNRS, LaMCoS, UMR 5259, F-69621 Villeurbanne, France \\ bUniv. Grenoble Alpes, CNRS, Grenoble INP, 3SR, F-38000 Grenoble, France \\ 'ENSAIT, GEMTEX, F-59056, Roubaix, France \\ ${ }^{d}$ ESRF -The European Synchrotron, Grenoble, F-38043 Cedex 9, France
}

\begin{abstract}
Flax fibre mats are promising and versatile biosourced reinforcements that can be used in composite parts obtained using various processing routes. To optimise their impregnation and the end-use properties of composites, it is still crucial to better understand the process-induced evolution of their microstructure and their permeability. In this study, flax fibre mats were subjected to in situ X-ray microtomography compression experiments. The resulting 3D images enabled the evolution of several key descriptors of their microstructure under compression to be determined, and the evolution of their permeability to be quantified by direct fibre scale CFD simulations. The microstructural data were also used as input parameters of a modified tensorial Kozeny-Carman model, accounting for the anisotropy and heterogeneity of mats. Only one unknown directional parameter was identified by inverse method from permeability calculations performed on numerically generated 3D realistic fibre networks. The predictions of the proposed model were consistent with numerical simulations.
\end{abstract}

Keywords: A. Natural fibres ; B. Permeability ; C. Numerical analysis ; D. CT analysis.

\section{Introduction}

Biosourced composites reinforced with plant-based fibres represent a credible alternative to composites reinforced with glass or other synthetic fibres that are commonly used as structural or semi-structural parts in many industrial applications [1] [2] [3] [4]. Several architectures of plant-based fibres are encountered [5] [6]: woven fabrics, knitted fabrics, and non-woven materials such as unidirectional veil of fibres and fibre mats. Fibre mats are versatile fibrous materials that consist of an intricate network of individualised fibrous elements such as 
discontinuous fibres, or discontinuous fibre bundles or both types of elements. The ease of their manufacturing offers the possibility to obtain various fibrous architectures varying for instance their fibre content, areal density and fibre orientation [7] [8]. In addition, they offer a good compromise with respect to other types of reinforcements because of their good processability (e.g. large deformation properties) in several composite manufacturing processes, and their ability to provide good reinforcement effect to polymer matrices [9] [10]. The manufacturing of composites parts with biosourced fibre mats can be done using either wet, e.g. Liquid Composite Moulding (LCM), or dry forming, e.g. compression moulding, processes [2][11][12][13]. These processes involve the deformation of these reinforcement materials and their simultaneous or subsequent impregnation by a fluid polymer matrix to obtain either a prepreg material or a composite part with the desired shape. For plant-based reinforcement materials such as flax fibre woven fabrics, a poor control of the deformation mechanisms of these materials in their dry state is known to induce several defects such as wrinkling, buckling or tearing that affect the reinforcement architecture and integrity [14] [15] [16]. Similarly, the impregnation of the same reinforcements by fluids such as filled thermoset resins or thermoplastics may result in voids inside and between tows [16] [17] [18] [19] [20] [21]. It has been established that the impregnation of fibrous reinforcements is mainly controlled by their anisotropic permeability properties [22] [23] [24] which are also strongly coupled with their deformation state [21][25][26]. The impregnation phenonema occurring in composite forming processes are usually modelled by assuming the Darcy's law [27] [28], which is, strictly speaking, valid for the flow of incompressible Newtonian fluids through rigid porous media at negligible Reynolds number. Vast research efforts are still ongoing to reveal the links between the components of the permeability tensor $\boldsymbol{K}$ of the Darcy's law and the deformability of various natural fibrous materials with more or less disordered architectures [29] [21]. For biosourced fibre mats, the prediction of the permeability components is all the more difficult to establish as the fibrous microstructure of these materials is strongly disordered and fibres exhibit large morphological variations [26] [30] [31].

Several experimental studies dealt with the determination of the out-of-plane and in-plane permeability of biosourced fibre mats [25] [31] [32] [33]. The effect of the compaction was also determined and allowed highlighting the effect of the porosity or conversely the fibre volume fraction on the permeability properties. Some authors reported that the evolution of the 
permeability components could be empirically fitted using either empirical power-law functions [21] [23] of the fibre volume fraction $\bar{\phi}_{s}$ or the Kozeny-Carman model [34] [35] [36]. This equation is widely used to estimate the permeability $K$ of isotropic porous media:

$$
K=\frac{\left(1-\bar{\phi}_{S}\right)^{3}}{2 c S_{v}^{2} \tau^{2}}
$$

where $S_{v}$ is the specific surface area, $\tau$ is the tortuosity (defined as the ratio between the mean flow path length and a characteristic length of the porous media). The Kozeny-Carman model assumes that the porous medium was equivalent to an assembly of parallel tortuous capillaries with equal length and diameter and circular cross sections. The assembly of capillaries has the same equivalent fibre volume fraction $\bar{\phi}_{s}$ and specific surface area $S_{v}$ as the porous medium. The parameter $c$ can be seen as a phenomenological corrective term to account for flows in cylinders with any cross section geometry [34] [35] [36] [37] [38] [39]. The Kozeny-Carman model was used by Bizet et al. [32] to fit the evolution of the out-of-plane permeability component of flax fibre mats by determining the best value for $c$ for fitting the experimental data. The parameter $c$ was shown to depend non-linearly on the fibre volume fraction.

The Kozeny-Carman equation thus relates the permeability to some key microstructure descriptors of the porous media and $c$, the parameter coupling the fluid flow with the structure. It is thus crucial to determine accurately these descriptors and their evolution with the deformation. Several studies used 3D X-ray microtomography imaging techniques to characterise the porous and fibrous architecture of biosourced mat [31] [40] [41] and paperlike materials [42] [43] [44]. Thanks to the analysis of 3D images, the authors could measure several crucial descriptors such as the mean porosity $\bar{\phi}_{p}$, the specific surface area $S_{v}$ and tortuosity $\tau$. They also used these parameters in the Kozeny-Carman equation and compared the prediction of this model for the out-of-plane permeability of wood-based fibre mats with results obtained experimentally or by numerical simulation performed on 3D X-ray microtomography images [31] [45]. The chosen value of the parameter $c$ did not allow a good prediction of the out-of-plane permeability of the studied materials [45]. Their choice was governed by considering geometry of the pore cross sections (circular or flat cross section of pores) that is presumably far from the real geometry of the pores in the investigated anisotropic fibrous networks. This shows that this parameter is critical and also difficult to estimate using 
uniquely image analysis of 3D fibrous networks. To circumvent this difficulty, Koponen et al. [46] performed flow simulations through the thickness of numerically generated realistic fibrous networks with planar fibre orientation representative of the structure of paper-like materials. Hence, they determined the out-of-plane permeability of these materials, thereby estimating the value of $c$ by an inverse method for this particular direction. They also proposed an empirical non-linear law for the evolution of $c$ as a function of the fibre volume fraction $\bar{\phi}_{s}$. Using high-resolution 3D X-ray microtomography images of fibre networks appear to be a powerful approach to estimate the permeability of fibrous materials with complex architectures [42] [43] [44] [47] [48] [49] [50] [51] [52]. The current progress made in 3D X-ray microtomography imaging allow acquiring 3D images during in situ and in real time experiments that mimic the real forming conditions the composite fibre reinforcements are subjected [53][54][55]. Hence, the objectives of this work were to investigate the microstructure and its evolution during transverse compression of thermolinked flax fibre mats, mimicking compaction phenomena that occur in many composite forming processes. For that purpose, in situ compression experiments were performed using synchrotron X-ray microtomography. Image analysis allowed quantifying the evolution of several key microstructure descriptors of the mats during their compaction. The components of the permeability tensor were estimated by direct numerical simulations on the 3D images for the various compression stages. Then, the microstructural data were used as input parameters of a modified anisotropic Kozeny-Carman model. To account for the anisotropy of the flax fiber mats, the tortuosity and an equivalent term to the aforementioned $c$ parameter of the KozenyCarman model were seen as directional parameters. Following the approach proposed by Koponen et al. [46], the directional values of $c$ were identified by an inverse method from permeability calculations performed using numerically generated 3D fibre networks. Finally, the relevance of the modified Kozeny-Caman model was discussed and was also tested for another type of biosourced mat. 


\section{Materials and methods}

\subsection{Flax fibre mats}

The first type of mat were made of 90 wt\% of flax fibres combined with 10 wt\% of polypropylene fibres. These mats, denoted M1 in the following sections, were fabricated by the Gemtex laboratory using carding, overlapping and needle punching nonwoven technologies [56] [57]. These mats were also consolidated using thermo-linking. During thermo-linking, the polypropylene fibres melted, allowing them to bond flax fibres after cooling. This process is usually used to increase the mechanical strength of mats. Fig. 1 shows microscopic views of the mats before and after thermo-linking. The areal density of these mats was $241 \mathrm{~g} \mathrm{~m}^{-2}$.

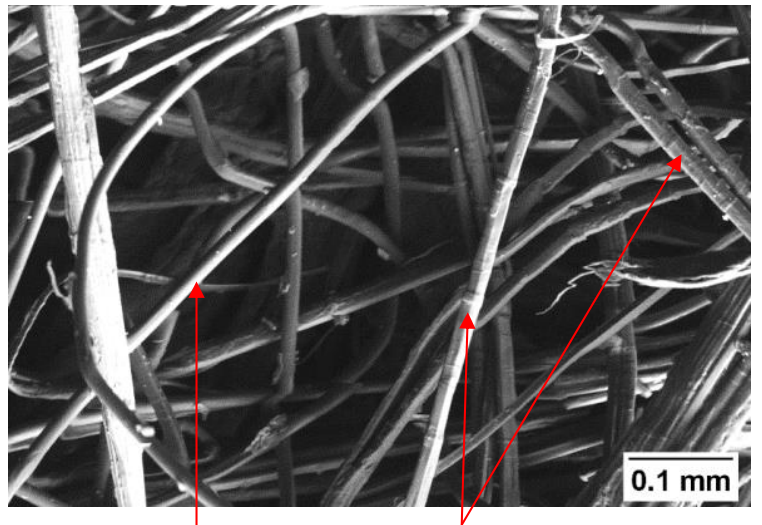

Polypropylene Flax fibre fibre

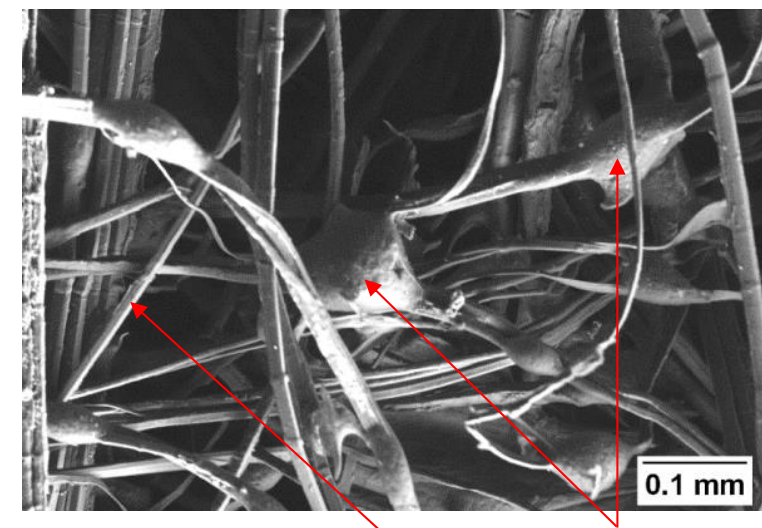

Flax fibre

(b)

Fig. 1. SEM micrographs of the mat M1 (a) before thermolinking and (b) after thermolinking.

A second type of flax fibre mat, denoted $\mathrm{M} 2$ in the following sections, was also used. This mat denoted Feutralin by the supplier Ecotechnilin (Valliquerville, France) had an areal density $G$ of $540 \mathrm{~g} \mathrm{~m}^{-2}$. This mat was also fabricated using carding, overlapping and needle punching processing techniques and was only made of flax fibres.

\subsection{In situ compression experiments and 3D image acquisition}

A specimen of mat M1 was subjected to out-of-plane compression tests using a micro-press installed on a synchrotron microtomograph (ID19 beamline, ESRF, Grenoble, France) [54] [58] [59]. This micro-press was equipped with a load cell with a maximum capacity of $50 \mathrm{~N}$ which allowed the compression force $F$ to be measured. The X-ray energy and the number of 
radiographs were set to $20 \mathrm{keV}$ and 2000 , respectively. A voxel size of $2.8^{3} \mu \mathrm{m}^{3}$ was chosen to obtain accurate representation of the fibrous microstructure of the mats. Then, 3D images were reconstructed using the so-called Paganin procedure, which is based on the use of the phase contrast in the images, required for so low absorbing materials [60] [61]. The specimen, initially in the form of a cylinder with a diameter of $10 \mathrm{~mm}$, was subjected to a slight precompression of $0.06 \mathrm{~N}$ to ensure contact with the platens. The thickness $h_{0}$ was about $0.8 \mathrm{~mm}$. Once a complete relaxation was reached, a first scanning experiment (Fig. 2, step A) was performed (scanning time $\approx 1 \mathrm{~min}$ ). Then, the specimen was sequentially put under compression up to a compression force of $6 \mathrm{~N}$ using a low compression velocity (Fig. 2, step B, the image was taken after a 10-min relaxation). The sample was further loaded to a compression force of $15 \mathrm{~N}$ (Fig. 2, step C, again the image was taken after a 10-min relaxation time). Finally, a fourth scan was carried out after unloading and relaxation (Fig. 2, step D). Fig. 2 also shows the stress-strain values as well as the 3D images of the specimen microstructure obtained during the compression test. The compression stress $\sigma_{z z}$ was calculated as the ratio $|F| / S_{0}$ with $S_{0}$ the initial contact area of the specimen surface with the compression platens. The compression strain was calculated as $\varepsilon_{z z}=\left|\ln \left(h / h_{0}\right)\right|$ with $h$ the sample thickness measured on the 3D images.

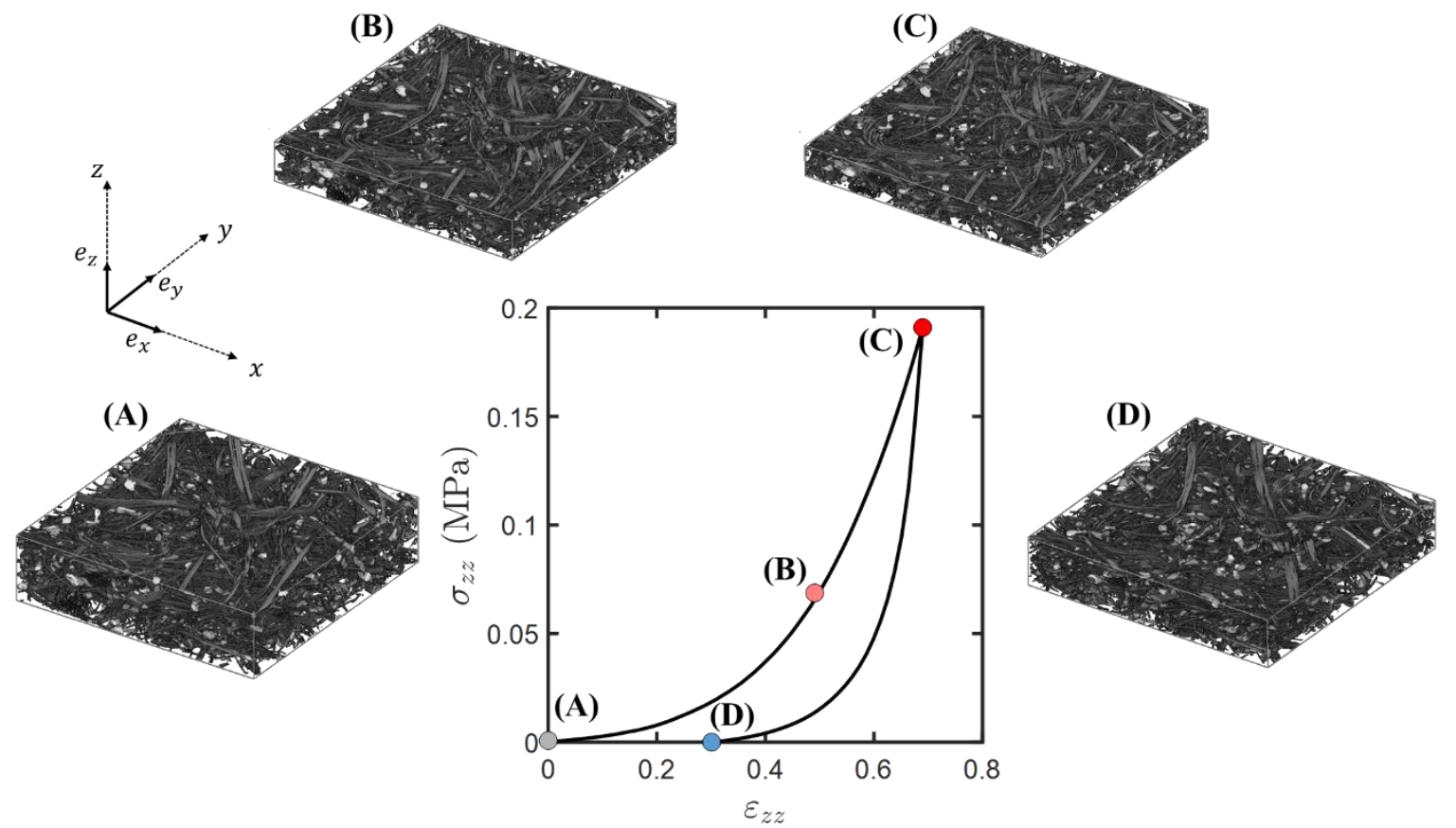

Fig. 2. A-D: $3 D$ cropped views of the fibrous microstructure of mat $M 1$ during in situ compression. The sizes of the $3 D$ images $A, B, C$ and $D$ are $3.1 \times 3.1 \times 0.8,3.1 \times 3.1 \times 0.5,3.1 \times 3.1 \times 0.4$ and $3.1 \times 3.1 \times$ $0.6 \mathrm{~mm}^{3}$, respectively. Graph: symbols $A, B, C$ and $D$ correspond to the recorded stress-strain values 
during the in situ compression test. The curve shows the compression response of another specimen of mat M1 obtained using the micro-press at low compression velocity.

\subsection{Image analysis and morphological characterization}

Thanks to the good contrast between the three imaged phases, i.e. the flax fibres, the polypropylene and pore phases, the 3D reconstructed images could be easily segmented. This operation was done manually using the threshold function implemented in Fiji Software [62]. The relevance of the thresholding operation will be discussed in section 3.1. Fig. 3 shows the segmented X-ray microtomography images of mat M1. Fig. 3d shows the evolution of the volume fraction of pores $\bar{\phi}_{p}$ as a function of the in-plane dimensions of the region of interest (ROI) chosen in the 3D images. This figure reveals that $\bar{\phi}_{p}$ was poorly affected by the size of the ROI for $l>1000 \mu \mathrm{m}$. This tends to show that above this size, the ROI's can be considered to be Representative Elementary Volume (REV) [44] [63]. In the following sections, the image analysis operations were performed for ROI's with $l=3080 \mu \mathrm{m}$ as shown in Figs. 2A-D.
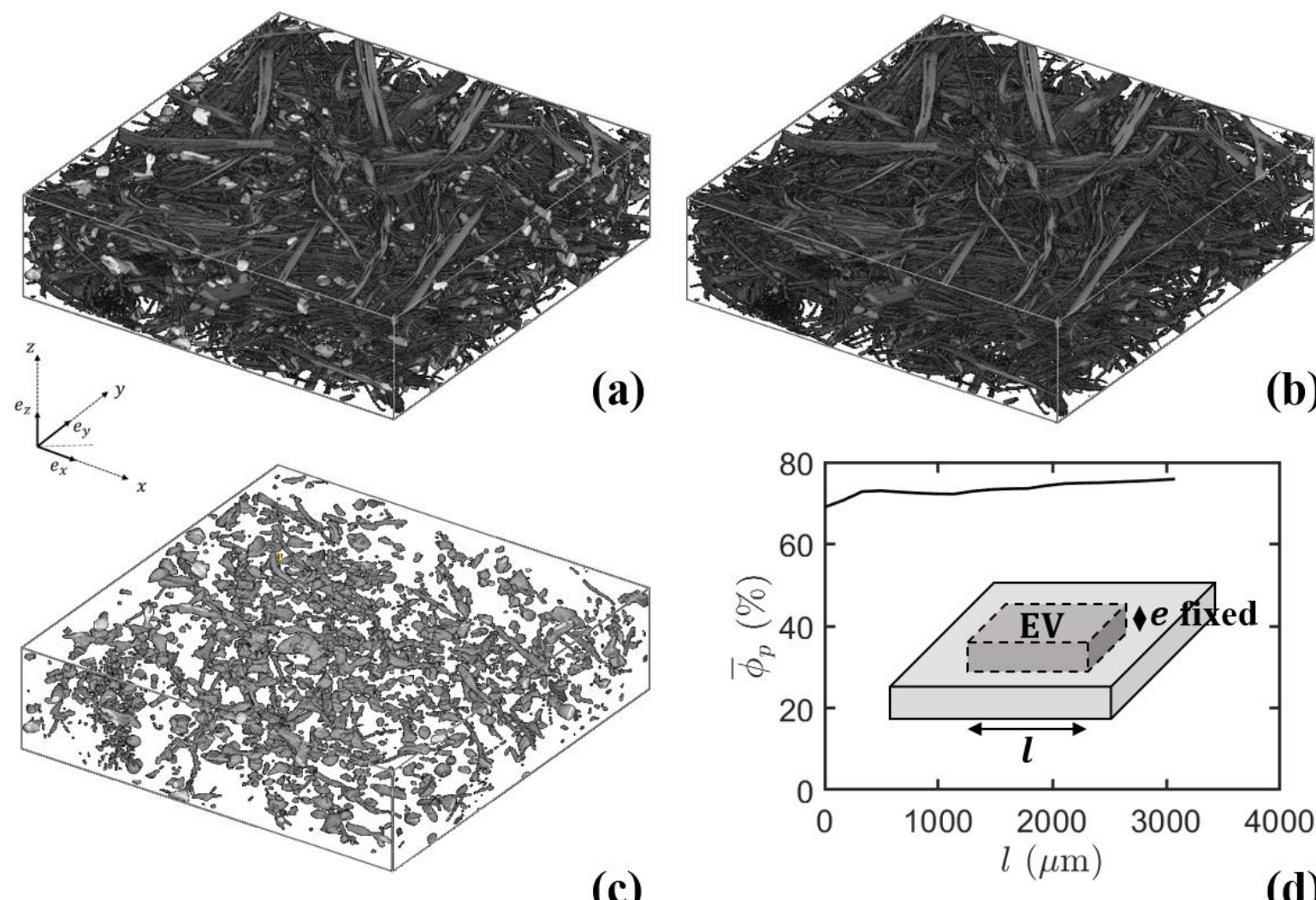

(b)

(c)

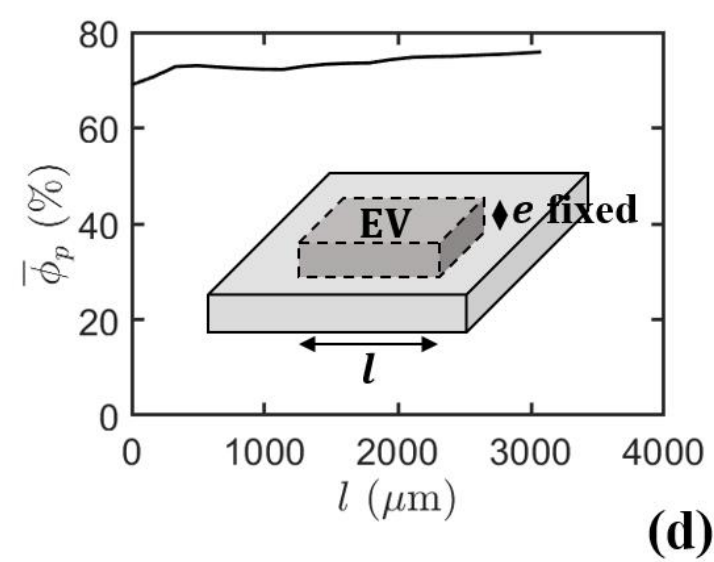

Fig. 3. (a) Segmented X-ray microtomography image of mat M1 after pre-compression showing in grey levels both the flax fibre phase and the polypropylene phase (size of the 3D images: $3.1 \times 3.1 \times 0.8 \mathrm{~mm}^{3}$ ). (b-c) Same images for the flax fibre and the polypropylene phases only. (d) Evolution of the mean pore volume fraction $\bar{\phi}_{p}$ as a function of the size of the in-plane length $l$ of the ROI. 


\section{Volume fraction of pores}

The local volume fraction of pores $\phi_{p}$ was calculated on each horizontal cross-section of the different 3D images obtained during compression (Figs. 2A-D) by dividing the number of voxels of this phase by the total number of voxels of the treated image. Similarly, the volume fraction of pores $\bar{\phi}_{p}$ was calculated on the different 3D images obtained during compression (Figs. 2AD) from the number of voxels of this phase divided by the total number of voxels of the treated image. In order to check the relevance of the thresholding operation, $\bar{\phi}_{p}$ was also estimated theoretically from Eq. (2):

$$
\bar{\phi}_{p}=1-\chi_{f} \frac{\rho_{m a t}}{\rho_{f}}-\chi_{p p} \frac{\rho_{m a t}}{\rho_{p p}}
$$

where $\rho_{\text {mat }}=G / h, \rho_{f}=1380 \mathrm{~kg} \mathrm{~m}^{-3}$ and $\rho_{p p}=910 \mathrm{~kg} \mathrm{~m}^{-3}$ [64] are the densities of the fibrous mat, flax fibres and polypropylene, respectively. The parameters $\chi_{f}=90 \%$ and $\chi_{p p}=10 \%$ are the mass ratios of flax fibres and polypropylene in the studied material, respectively.

\section{Volumetric size distributions}

The volumetric size distributions of the diameters $d$ of flax fibres, solid phase (flax fibres plus melted polypropylene fibres) and pore sizes were estimated using the function 3D granulometry [65] [66] [40] [67] implemented in the plugin Analysis 3D in Fiji [68]. These measurements were performed using octahedron structural elements [67].

\section{Specific surface area $\boldsymbol{S}_{v}$}

A stereological technique [69] [65] based on the use of intercept lines was used to estimate the specific surface area $S_{v}$ of the solid phase, i.e. flax fibre phase plus the polypropylene phase. The specific surface density was calculated as follows [70]:

$$
S_{v}=2 \overline{P_{L}}
$$

where $\overline{P_{L}}$ is the mean number of intercepts per unit of intercept lines. $\overline{P_{L}}$ was calculated from the measurements of the number of intersection with the solid phase of 500 intercept lines the directions of which were randomly distributed in the orientation space and crossing at the center of the samples. For this number of intercept lines, the values of $S_{v}$ was stabilized.

\section{Directional tortuosities $\boldsymbol{\tau}_{i i}$}


The directional tortuosities $\tau_{x x}, \tau_{y y}$ and $\tau_{z z}$ of the pore phases of the studied mats were calculated along the directions $\boldsymbol{e}_{x}, \boldsymbol{e}_{y}$ and $\boldsymbol{e}_{z}$ of the 3D images, using the plugin Tortuosity [71] implemented in Fiji software. More details are given in ref. [70].

\subsection{Permeability estimation using 3D images and CFD simulation}

The components of the permeability tensor $K$ of the mats $\mathrm{M} 1$ and $\mathrm{M} 2$ and the virtual fibrous mats that were numerically generated were calculated numerically using the CFD module FlowDict of the Finite Volume software GeoDict and the Explicit Jump-Stokes (EJ-Stokes) solver. Within this numerical package, the localization Stokes flow problems, deduced from the homogenization method with multiple scale asymptotic expansions [72] [73] [74], were solved within the pore phase of the 3D X-ray microtomography binarized images of the different fibrous materials (Fig. 2). The local velocity field as well as the first-order pressure fluctuation field were considered as in-plane periodic and the macroscale pressure-gradient was imposed [47] [75] [76]. More details about the numerical procedure are reported by Chalencon et al. [76]. For illustration purpose, Fig. 9a shows the norm of the stationary velocity field obtained by numerical simulation for a fluid flow along $\boldsymbol{e}_{z}$ direction through the mat M1 in its initial state. Using such approach, it can be inferred from the statistical analysis by Jeulin [77] that the relative error for the predicted components of the dimensionless permeability tensor (Tab. 1) is about $10 \%$ to $15 \%$. The analysis by Jeulin relates the relative error of a property (e.g. the components of the permeability tensor) to the size of the volume used to calculate the property, the number of calculations and the evolution of the variance of the property with the size of the calculation volume. Decain [78] and Marulier [79] used a similar approach for the predictions of the thermal and mechanical properties of cellule-based fibrous materials and confirmed the relevancy of this approach to estimate the relative error.

\section{Results}

\subsection{Analysis of the microstructure of mat M1 under compression}

\section{Evolution of the pore volume fraction}

Fig. 4a shows the variation of the local volume fraction of pores $\phi_{p}$ along the thickness of the sample for the different stages of compression shown in Fig. 2. This figure shows that the volume fraction of pores decreases with the increase in the compression loading and increases 
after unloading. However, in the initial state and during the deformation of the sample, the volume fraction of pores varies slightly along the thickness. After unloading, the volume fraction of pores is different from that in the initial state. This type of evolution of the microstructure has already been observed for other types of fibre reinforcements [80] [81]. Fig. $4 \mathrm{~b}$ shows that the mean value of the volume fraction of pores $\bar{\phi}_{p}$ calculated from the data shown in Fig. 4 a decreases with the increase in the compression strain $\varepsilon_{z z}$. These results also show a good agreement with the predictions of Eq. (2). This tends to show that the thresholding of the 3D images was accurate as well as the estimate of the pore volume fractions.

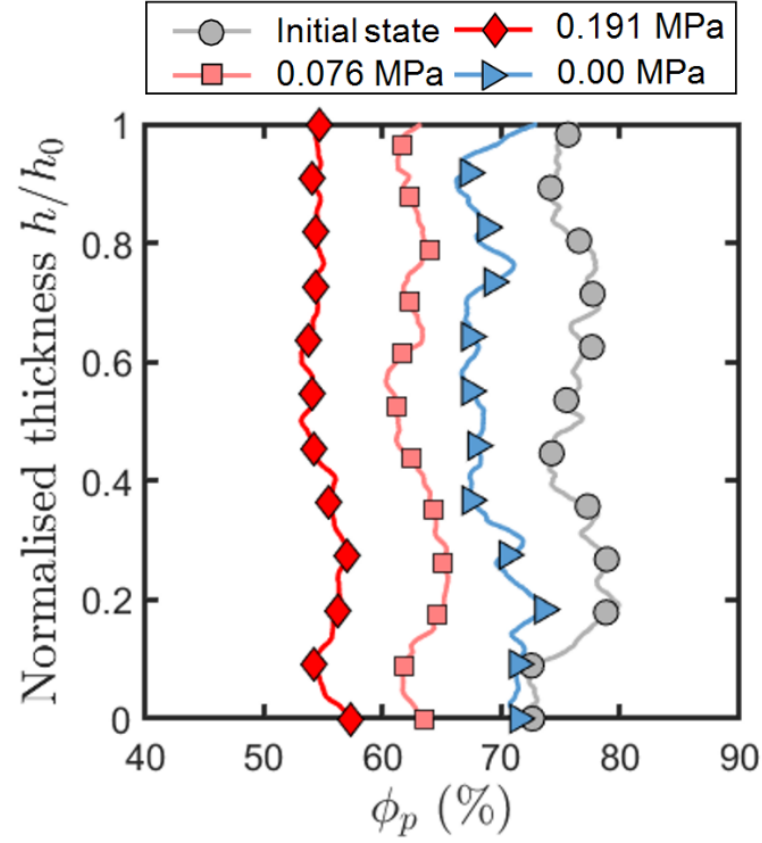

(a)

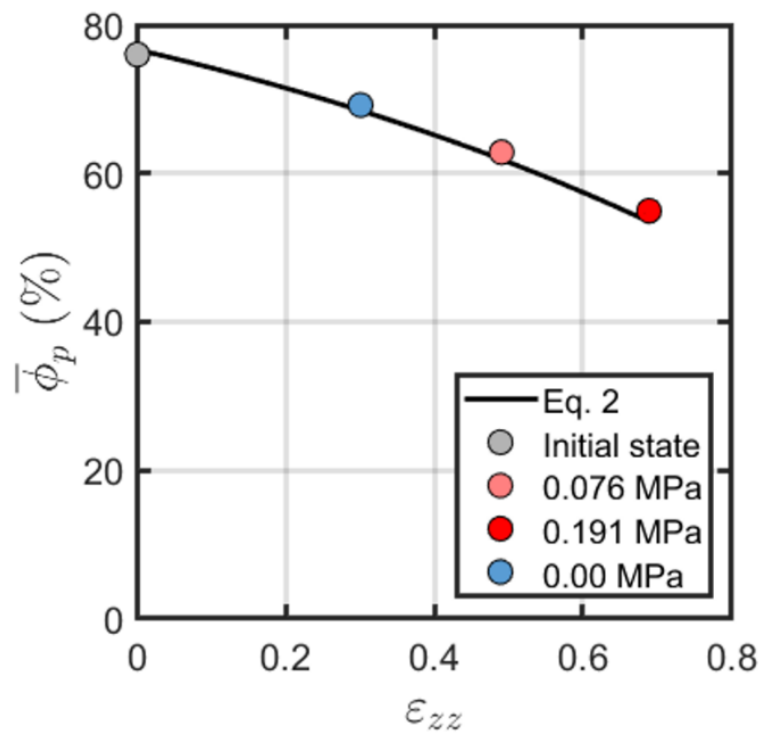

(b)

Fig. 4. Mat M1 - (a) Variation of the local volume fraction of pores $\phi_{p}$ along the normalised thickness. (b) Evolution of the mean volume fraction of pores $\bar{\phi}_{p}$ as a function of the compressive strain $\varepsilon_{z z}$.

\section{Evolution of the volumetric distributions of pore, fibre and solid phases}

The evolution of the volumetric pore distributions reveals a decrease in the pore sizes and a decrease in the width of the distributions with the increase in the compressive strain $\varepsilon_{z z}$. (Fig. 5a). This is further confirmed by the evolution of the mean value of the pore sizes, as shown in Fig. $5 \mathrm{~d}$. This shows the densification of the mat M1 with the compression loading. In addition, the volumetric pore size distribution after unloading (stage D) do not superimpose to that of the initial state (stage A). This phenomenon has to be related to the aforementioned evolution 
of the porosity and is certainly due to rearrangements in the fibre network of mat M1. This is confirmed by the results shown in Figs. $5 b$ and $5 d$ which reveal that both the volumetric fibre diameter distribution and the mean fibre diameter remain almost unchanged during compression. This tends to show that the fibre cross sections did not collapse during compression. Note also the mean value of flax fibre diameter $\bar{d}_{f}$ was around $28 \mu \mathrm{m}$, which is accordance with the observations made from SEM images (Fig. 1). This value is also in agreement with those reported by several authors for elementary flax fibres [82][83]. Similarly, the volumetric distributions that were measured on the solid phase did not vary significantly during the compression test (Fig. 5c). As expected, the mean thickness of the solid phase (flax fibres plus melted polypropylene fibres) $\bar{d}_{s}$ was higher than $\bar{d}_{f}$, i.e. close to $40 \mu \mathrm{m}$. 


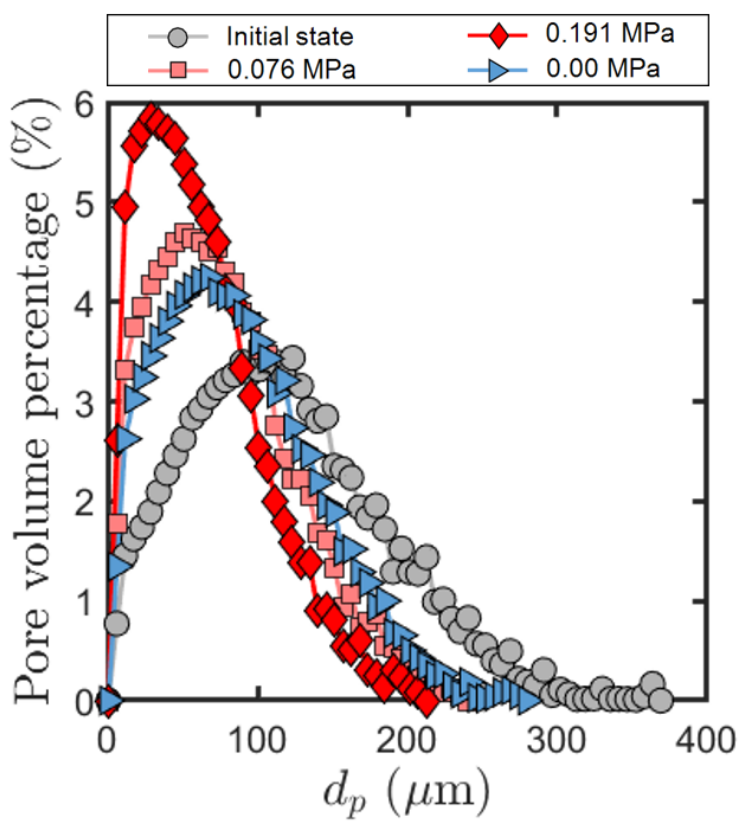

(a)

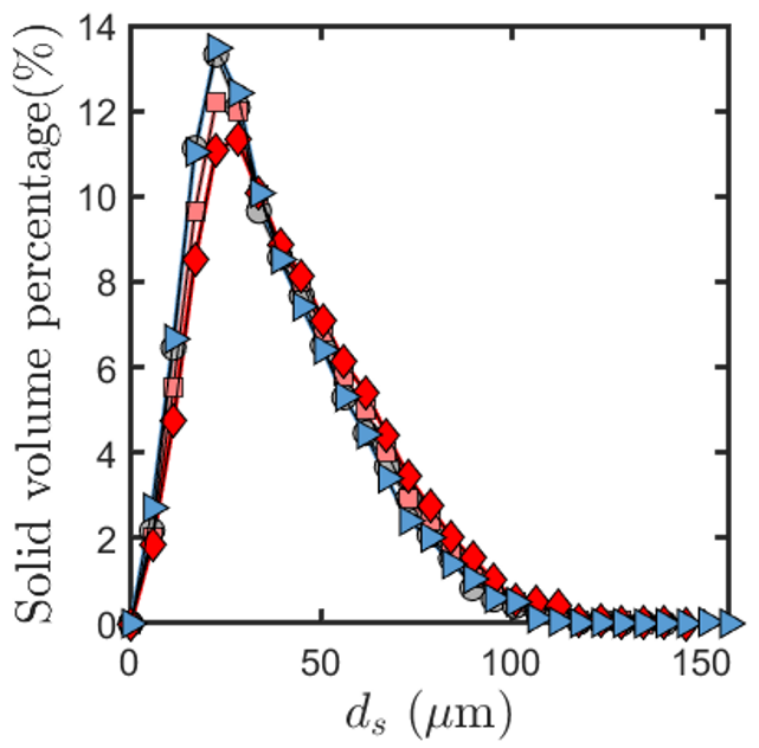

(c)

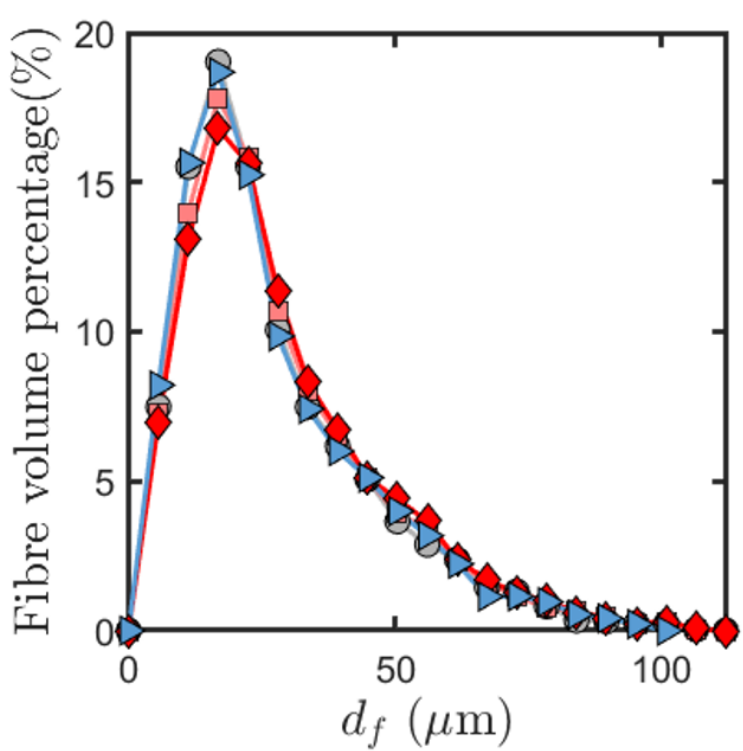

(b)

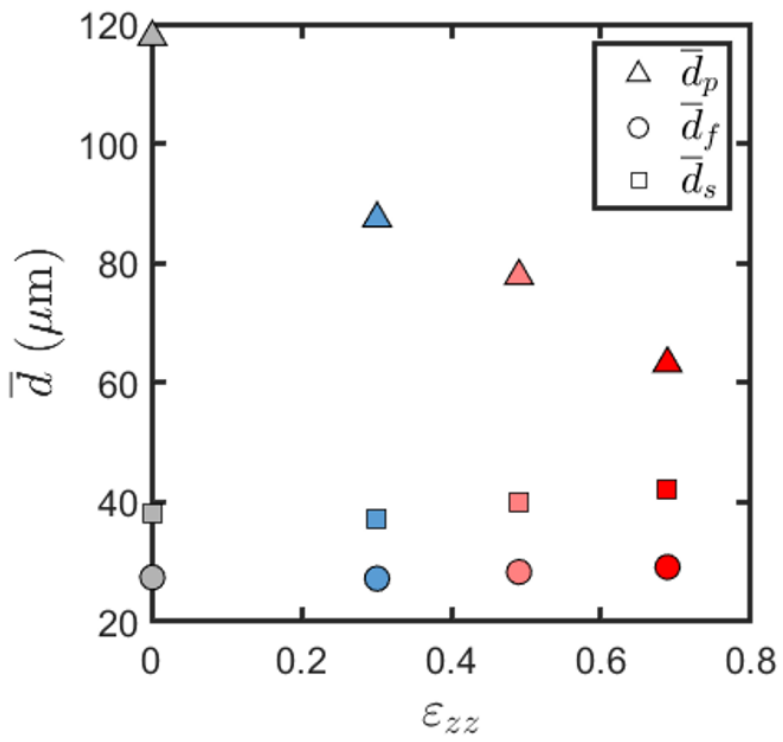

(d)

Fig. 5. Mat 1 - Volumetric distributions of (a) the sizes of the pores $d_{p}$, (b) the diameters of flax fibres $d_{f}$ and (c) the thicknesses of the solid phase (flax fibres plus melted polypropylene fibres) $d_{s}$. (d) Evolution of the mean size of pores $\bar{d}_{p}$, mean diameter of flax fibres $\bar{d}_{f}$ and mean thickness of the solid phase $\bar{d}_{s}$ as a function of the compressive strain $\varepsilon_{z z}$.

\section{Specific surface area $\boldsymbol{S}_{v}$}

Fig. 6 shows that the specific surface area $S_{v}$ increases non-linearly with the increase in the solid phase volume fraction $\bar{\phi}_{s}$. The values for $S_{v}$ are close to those reported for others types 
of fibrous materials with similar solid volume fractions $\bar{\phi}_{s}$ such as wood fibre mats [31] [45] or papers [84]. The increase of $S_{v}$ can be explained by the compaction of the sample of mat M1 with the compression loading. The compaction induces a decrease in the thickness $h$ and in the volume of the sample, which results in a higher specific surface area. The compaction effect can be counterbalanced by the creation of new contacts between the fibres of the mat, thus decreasing the overall surface area of the solid phase. These two opposite effects could be at the origin of the slightly non-linear evolution of $S_{v}$ with the volume fraction of the solid phase $\bar{\phi}_{s}$. The effects of possible rearrangement mechanisms is also visible in Fig. 6 as the value of $S_{v}$ after unloading (stage D) do not superimpose to that of the initial state (stage A).

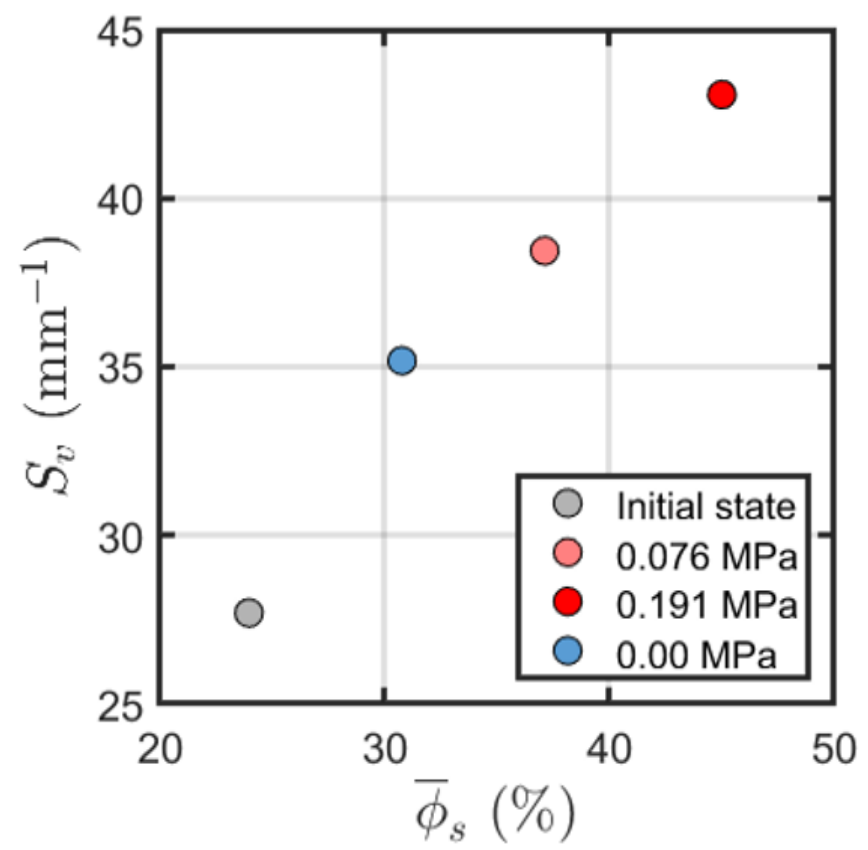

Fig. 6. Evolution of the specific surface area of mat M1 as a function of the mean volume fraction of the solid phase $\bar{\phi}_{s}$.

\section{Directional tortuosities $\tau_{x x}, \tau_{y y}$ and $\tau_{z z}$}

Fig. 7 shows that the directional tortuosities $\tau_{x x}, \tau_{y y}$ and $\tau_{z z}$ increase with increasing the volume fraction of the solid phase $\phi_{s}$, i.e. the paths followed by a particle in the pore phase from one side to the opposite side of the sample would become longer with the increase in the compaction. In addition, the out-of-plane tortuosity $\tau_{z z}$ is higher than the in-plane tortuosities $\tau_{x x}$ and $\tau_{y y}$ that have similar values and follow the same evolution with $\phi_{s}$. This reveals the transverse isotropy of mat M1 for this property. Note that the orders of magnitude of the 
tortuosities $\tau_{x x}, \tau_{y y}$ and $\tau_{z z}$ are in accordance with those reported by Peyrega and Jeulin [85] for similar fibrous materials with in-plane fibre orientation.

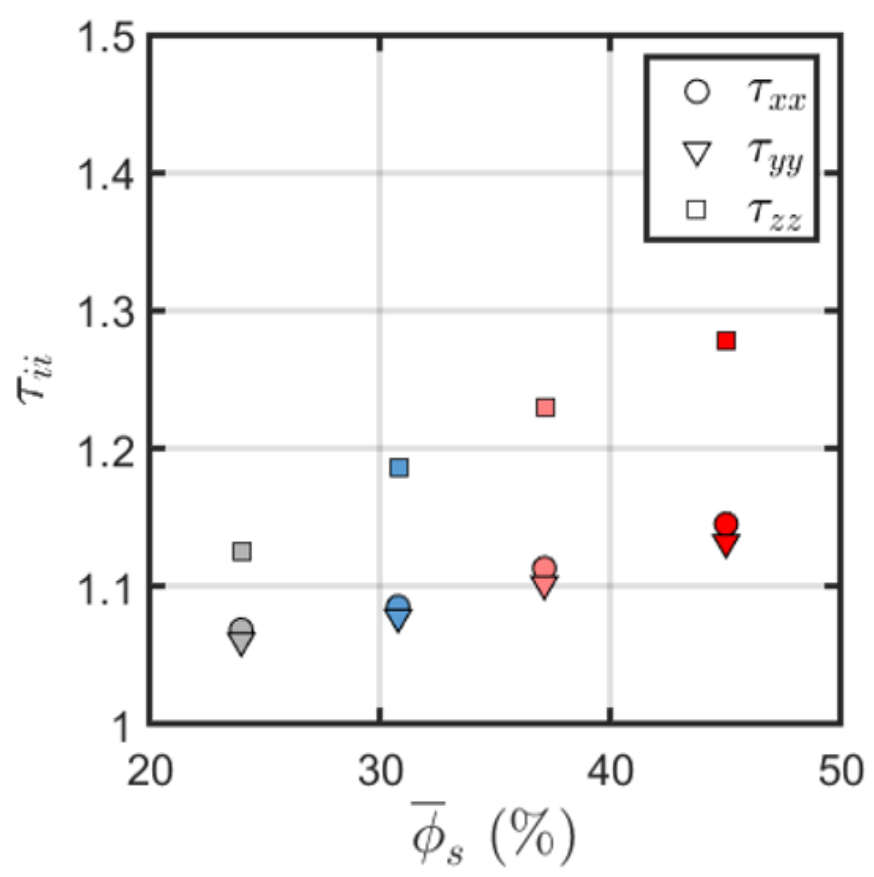

Fig. 7. Evolution of the directional tortuosities $\tau_{x x}, \tau_{y y}$ and $\tau_{z z}$ of mat $M 1$ as a function of the solid volume fraction $\bar{\phi}_{S}$.

\subsection{Numerical permeability estimates}

Tab. 1 gives values of the components of the dimensionless permeability tensors $\left(\boldsymbol{K}^{*}=\frac{1}{\bar{r}_{S}^{2}} \boldsymbol{K}\right.$, with $\bar{r}_{s}=\bar{d}_{s} / 2=20 \mu \mathrm{m}$, see Fig. $5 \mathrm{~d}$ ) obtained by numerical simulation for the different compression stages of mat M1. The diagonal components of $\boldsymbol{K}^{*}$, i.e. $K_{x x}^{*}, K_{y y}^{*}$ and $K_{z z}^{*}$, are greater of at least one order of magnitude than the non-diagonal components. The components $K_{x x}^{*}$ and $K_{y y}^{*}$ are also very close to each other regardless of the compression state. This tends to show that mat M1 initially exhibits transverse isotopy for the permeability and that the directions $\boldsymbol{e}_{x}, \boldsymbol{e}_{y}$ and $\boldsymbol{e}_{z}$ (Fig. 2) are the principal directions of the permeability tensor. Note that the permeability components show a decrease with increasing the compression and that they tend to reach the same values for the highest compression level. In this case the permeability tensor is almost isotropic.

Table 1. Components of the dimensionless permeability tensor $\boldsymbol{K}^{*}=\frac{1}{\bar{r}_{s}^{2}} \boldsymbol{K}$ obtained for the mat M1 for the different compression stages in the $\left(\boldsymbol{e}_{x}, \boldsymbol{e}_{y}, \boldsymbol{e}_{z}\right)$ frame shown in Fig. 2. 


\begin{tabular}{|l|c|}
\hline & Dimensionless permeability tensors \\
\hline Initial state (Fig. 2A) & {$\left[\boldsymbol{K}^{*}\right]=\left[\begin{array}{ccc}0.36 & 0.02 & -0.01 \\
0.02 & 0.41 & 0.00 \\
-0.01 & 0.00 & 0.27\end{array}\right]_{\left(\boldsymbol{e}_{x}, \boldsymbol{e}_{y}, \boldsymbol{e}_{z}\right)}$} \\
\hline $0.076 \mathrm{MPa}$ (Fig. 2B) & {$\left[\boldsymbol{K}^{*}\right]=\left[\begin{array}{lll}0.10 & 0.00 & 0.00 \\
0.00 & 0.11 & 0.00 \\
0.00 & 0.00 & 0.09\end{array}\right]_{\left(\boldsymbol{e}_{x}, \boldsymbol{e}_{y}, \boldsymbol{e}_{z}\right)}$} \\
\hline $0.191 \mathrm{MPa}$ (Fig. 2C) & {$\left[\boldsymbol{K}^{*}\right]=\left[\begin{array}{lll}0.05 & 0.00 & 0.00 \\
0.00 & 0.05 & 0.00 \\
0.00 & 0.00 & 0.05\end{array}\right]_{\left(\boldsymbol{e}_{x}, \boldsymbol{e}_{y}, \boldsymbol{e}_{z}\right)}$} \\
\hline $0.00 \mathrm{MPa}$ (Fig. 2D) & {$\left[\boldsymbol{K}^{*}\right]=\left[\begin{array}{lll}0.17 & 0.01 & 0.00 \\
0.01 & 0.18 & 0.00 \\
0.00 & 0.00 & 0.14\end{array}\right]_{\left(\boldsymbol{e}_{x}, \boldsymbol{e}_{y}, \boldsymbol{e}_{z}\right)}$} \\
& \\
&
\end{tabular}

\section{Discussion}

\subsection{Proposition of an anisotropic Kozeny-Carman permeability model}

Based on the previous studies devoted to the prediction of the permeability properties of fibrous materials with disordered fibrous architectures such as papers [46], boards or reinforcement for composites made of discontinuous fibres [31] [45] [48] [49] [86], we propose the following adaptation of the Kozeny-Carman (KC) model for anisotropic porous materials where the principal components of the dimensionless permeability tensor $K_{i}^{*}$ are written as follows:

$$
K_{i}^{*}=\frac{\left(1-\bar{\phi}_{s}\right)^{3}}{2 c_{i} S_{v}^{2} \tau_{i}^{2}} \frac{1}{{\overline{r_{s}}}^{2}}
$$

with $i=I, I I, I I I$ (no summation on $i$ ). In this expression, the terms $c_{i}$ represent directional equivalent terms to the scalar parameter $c$ of the classical KC model (cf. Eq. 1).

Following the approach proposed by Koponen et al. [46], we propose to identify the components $c_{i}$ using for that an inverse calculation method. This method consists in (i) generating a set of Representative Elementary Volumes (REV) of fibrous media with random inplane fibre orientations and various fibre volume fractions $5 \%<\bar{\phi}_{s}<60 \%$, (ii) calculating the principal components of the permeability tensor $K_{i}^{*}$ of these REV's as well as (iii) the directional 
tortuosities $\tau_{i}$ in the anisotropy directions of the permeability tensor, i.e. along $\boldsymbol{e}_{x}, \boldsymbol{e}_{y}, \boldsymbol{e}_{z}$ the principal orientation directions of the generated fibrous media (Fig. 8a), and the specific surface area $S_{v}$, adopting the same approach to that used for the mat M1. Finally, the directional components $c_{i}$ were identified as a function of $\phi_{s}$.

Figs. 8a,b show that the specific surface area $S_{v}$ and directional tortuosities $\tau_{i}$ of the numerically generated idealized fibrous mats well correspond to those measured for the mat M1. The origin of the slight differences observed can be due to the presence of the melted PP phase within the mat M1 that slightly modifies the fibrous and porous architectures. However, the dimensionless permeability components $K_{i}^{*}$ (Fig. 8c) are in the same order of magnitude as those of the mat M1 (Tab. 1). These results tend to show that the generated REV's represent quite well the real microstructures of the flax fibre mats. Finally, using the data obtained for the numerically generated REV's, it was possible to identify the evolution of the in-plane and out-of-plane values $c_{i}$ as a function of $\bar{\phi}_{s}$ (Fig. 8d). The following empirical functions were determined by the least squares method to fit the values obtained for these components:

$$
\begin{gathered}
c_{I}\left(\bar{\phi}_{S}\right)=c_{I I}\left(\bar{\phi}_{S}\right)=-10\left(1-e^{-\frac{\bar{\phi}_{S}}{0.07}}\right)+11.55 \\
c_{I I I}\left(\bar{\phi}_{S}\right)=-11\left(1-e^{-\frac{\bar{\phi}_{S}}{0.07}}\right)+12.9
\end{gathered}
$$

The values of $c_{I I I}$ that were calculated are close to that obtained by numerical simulation by Koponen et al. [46] for generated paper networks with a fibre volume fraction $\bar{\phi}_{s}$ that ranges between 0.2 and $0.5\left(c_{I I I} \approx 2.8\right)$. The slight difference is presumably due to the rectangular geometry of the cross section of the fibres of the networks considered by Koponen et al. [46]. Note also that these authors did not correct the values of $c_{I I I}$ by accounting for the out-ofplane tortuosity $\tau_{I I I}$ of the networks. 


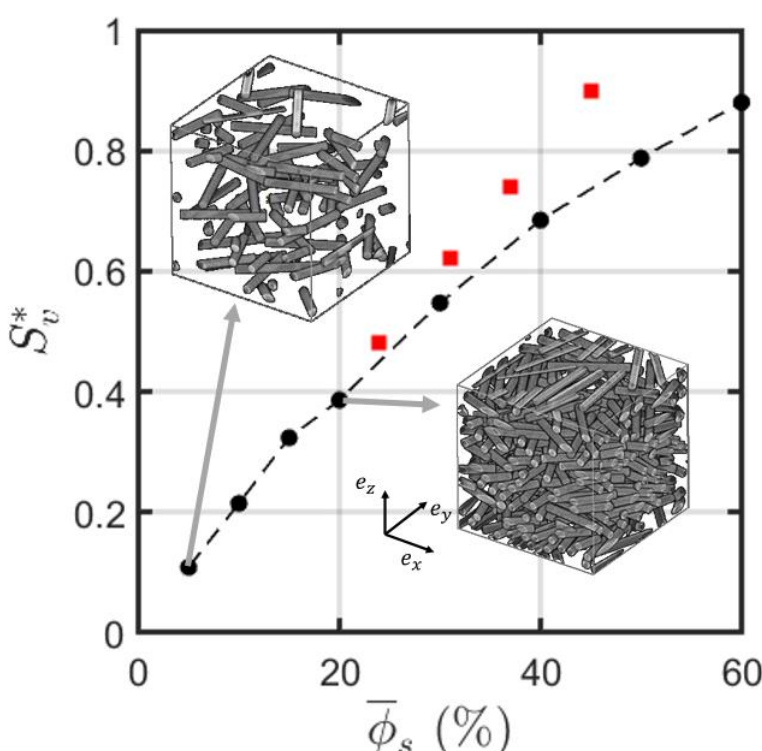

(a)

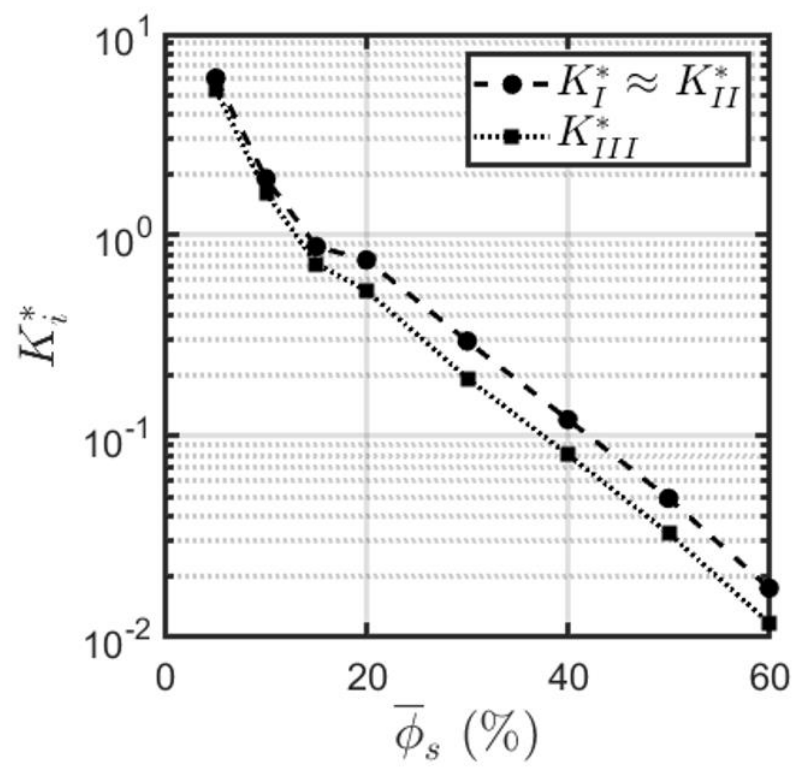

(c)

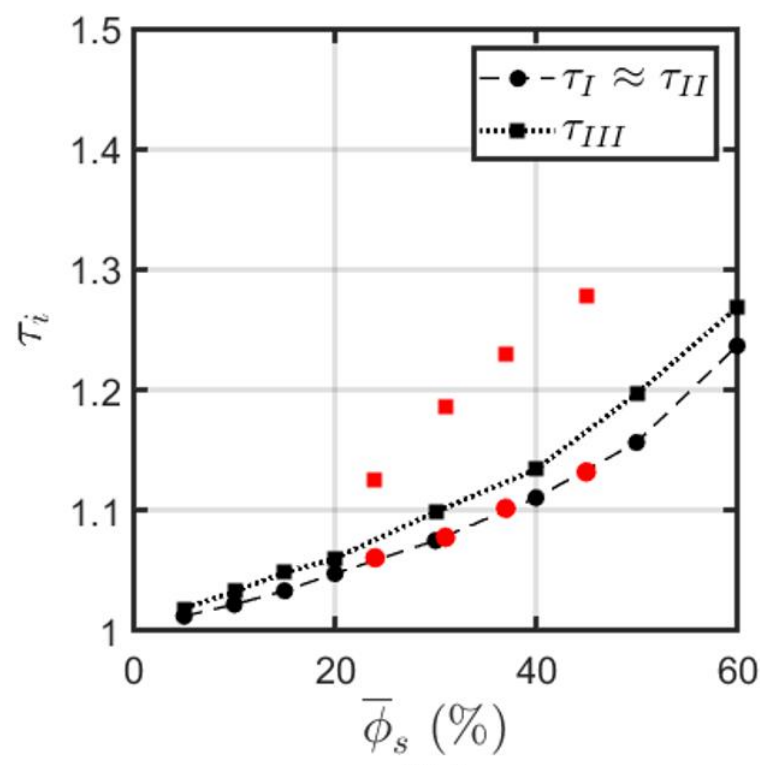

(b)

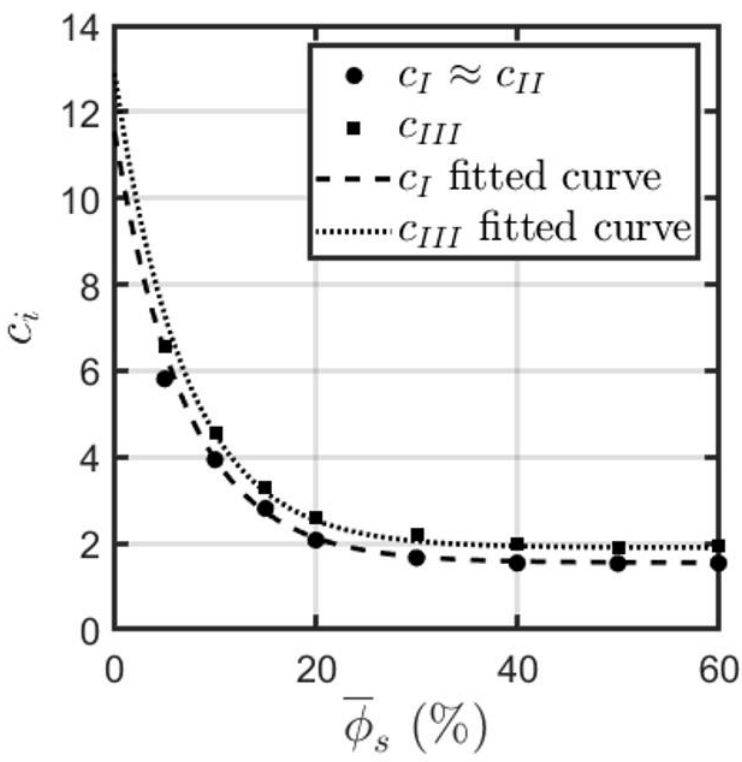

(d)

Fig. 8. (a) Dimensionless specific surface area $S_{v}^{*}=S_{v} \bar{r}_{s}$, (b) directional tortuosities $\tau_{i}$, (c) dimensionless permeability components $K_{i}^{*}$ and (d) directional values $c_{i}$ as a function of the solid volume fraction $\bar{\phi}_{s}$ obtained for the numerically generated REV's of fibrous media. Note that the REV's were generated numerically using the microstructure generator FiberGeo of software GeoDict which is based on a softcore approach. The calculations of the permeability components were performed using the module FlowDict of this software (as explained in section 2). For comparison purpose, the colored symbols correspond to the values obtained for the mat M1. 


\subsection{Model predictions and validation}

The principal components of the permeability tensors were estimated for the mat M1 using the modified KC model and the expressions of $c_{i}$ obtained for the numerically generated REV's, whereas the specific surface area, directional tortuosities and the fibre volume fraction were obtained from the analysis carried out in Section 3. Fig. 9b shows the principal components of the dimensionless permeability tensor obtained by the numerical simulation and the prediction of the modified $\mathrm{KC}$ model. The relative errors between the numerical values and the $\mathrm{KC}$ predictions are below approximately $18 \%$ for all the components $K_{I}^{*}, K_{I I}^{*}$ and $K_{I I I}^{*}$, (Fig. 9c), which is fairly reasonable. Thus, both sets of values are in accordance regardless of the fibre volume fractions reached during the compression experiments.

Furthermore, the prediction of the modified KZ model was tested for the mat M2 (Figs. 9b,c). This mat is only composed of flax fibres and is not thermolinked (Fig. 9d). Using again 3D X-ray microtomography images (resolution: $6.5^{3} \mu^{3}$, Tomcat beamline, Paul Scherrer Institute, Villigen, Switzerland), the following microstructural characteristics were determined: $\bar{\phi}_{S}=$ $0.28, S_{v}=20.4 \mathrm{~mm}^{-1}, \tau_{I}=1.07, \tau_{I I}=1.08, \tau_{I I I}=1.13$ and $\bar{d}_{f}=\bar{d}_{s}=54 \mu \mathrm{m}$. Both the predictions of the modified KC model and the numerical predictions are in good agreement for this other type of flax fibre mat. 


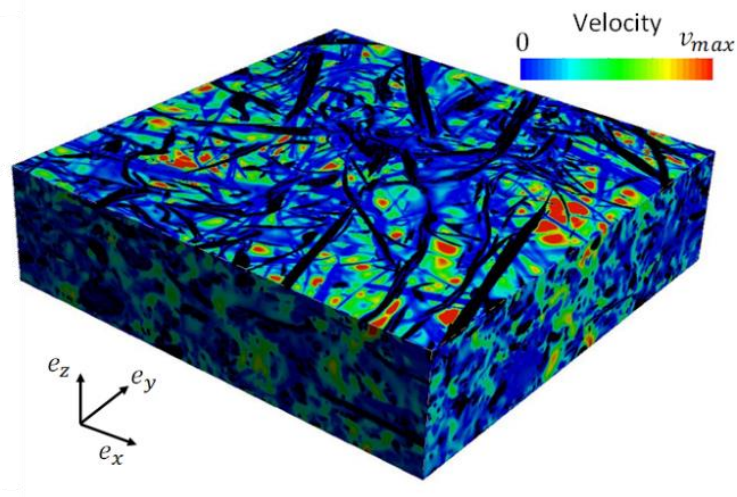

(a)

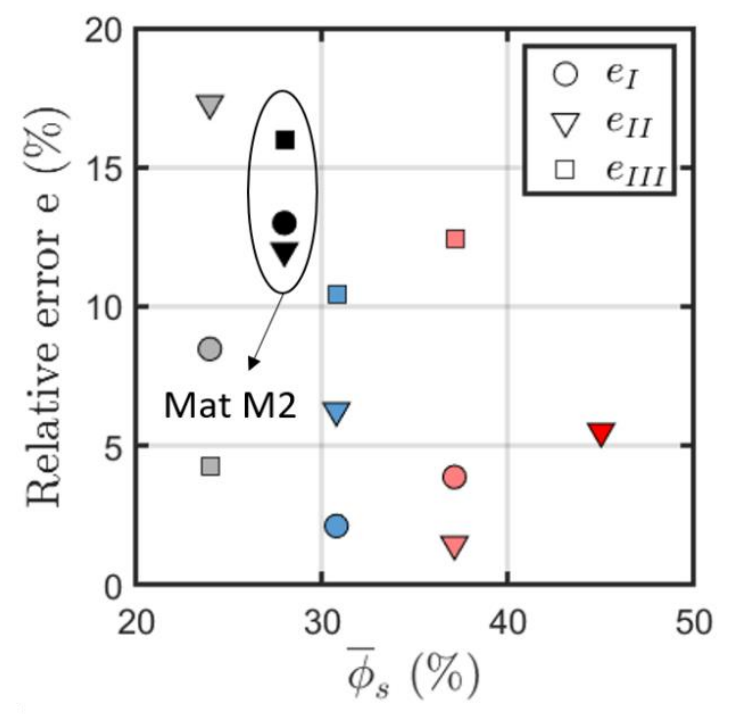

(c)

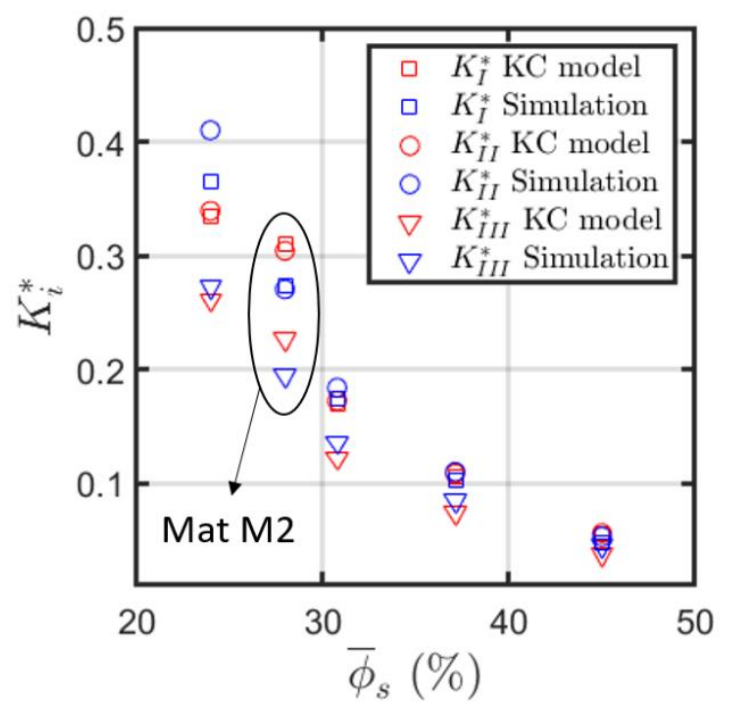

(b)

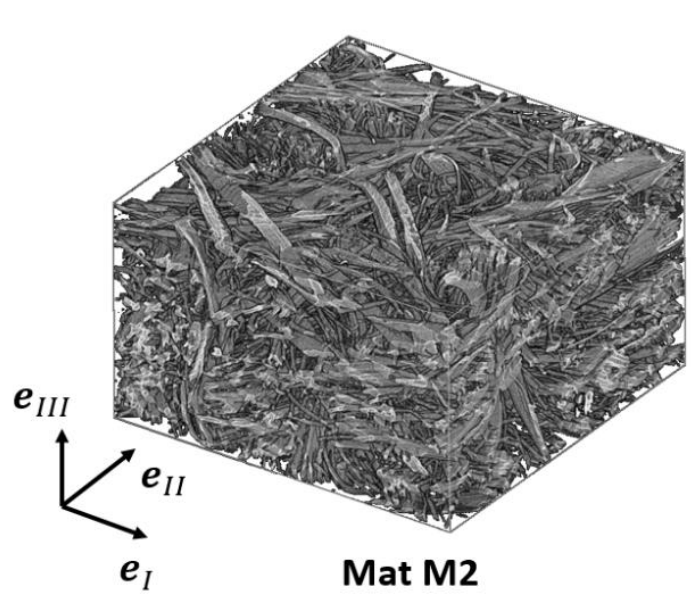

(d)

Fig. 9 (a) Norm of the velocity field corresponding to a transverse fluid flow through the fibrous mat M1 in its initial state. (b) Dimensionless permeability components: modified KC model and Geodict numerical simulation results. (c) Relative error between the numerical and theoretically estimated permeability components. (d) 3D microtomography images showing the fibrous microstructure of the mat M2.

\section{Conclusion}

In situ out-of-plane compression tests were performed on a thermolinked flax fibre mat, using a micro-press installed on a synchrotron microtomography beamline. This technique allowed us to show that (i) the porous phase evolved significantly as shown by the measurements of 
the mean porosity, pore size distribution, and components of the directional tortuosities (ii) the cross sections of the flax fibres remained almost unchanged, (iii) and the specific surface area increased with increasing the compaction. The changes of the porous phase are not totally reversible as shown by the analysis of the unloading stage. The 3D images were also used as input data to numerically calculate the principal components of the permeability tensor of the studied fibrous mats and their evolution during compression. The simulation results showed that the permeability is transversely isotropic with principal axes that did not evolve during compression.

In parallel, a modified Kozeny-Carman model taking into account the transverse anisotropy of the permeability tensor was proposed. This model accounts for parameters such as the fibre volume fraction, specific surface area, directional tortuosities and several directional terms $c_{i}$ that are related to the heterogeneity and the variations in the porous anisotropic structure that induce fluid flow perturbation. All parameters of this model could be identified from the analysis of 3D images, except the in-plane and out-of-plane values $c_{i}$. To identify them a set of fibrous mats were numerically generated for a wide range of fibre volume fractions $\bar{\phi}_{s}$. Expressions of the in-plane and out-of-plane values $c_{i}$ were proposed as a function of the fibre volume fraction $\bar{\phi}_{s}$. The permeability values obtained by this model were consistent with those obtained by numerical simulation for all the investigated compression state of the thermolinked flax fibre mat. This model also allowed a good prediction of the permeability of another type of mat with a different fibrous architecture and only composed of flax fibres using 3D images acquired at lower spatial resolution.

This study shows that using 3D X-ray microtomography images, it is possible to identify nearly all the parameters of a Kozeny-Carman-like permeability model well adapted for materials that exhibit disordered fibrous microstructure with varying size and shape of the fibre elements and consequently a complex porous architecture for which microstructure models for, e.g. the surface specific area do not exist. It would be interesting to test this model for a larger set of fibrous mats subjected to various deformation modes such as those encountered in composite forming processes. 


\section{Acknowledgements}

C. Balbinot gratefully acknowledges the French Ministry of Higher Education and Research for her PhD research grant. We acknowledge EcoTechnilin (Valliquerville, France) and would like to thank Karim Behlouli for supplying mat M2. The experiments done on mat M1 were performed on beamline ID19 at the European Synchrotron Radiation Facility (ESRF) in the framework of the long term project "Heterogeneous fibrous materials" (MA 127), Grenoble, France. We acknowledge the Paul Scherrer Institut (PSI), Villigen, Switzerland for provision of synchrotron radiation beamtime at beamline TOMCAT of the SLS and would like to thank Anne Bonnin for assistance for the experiments done on mat $\mathrm{M} 2$. The authors also endorse the research site of INSA Lyon at Oyonnax for administrative and technical support. The laboratory 3SR is part of the LabEx Tec 21 (Investissements d'Avenir -grant agreement n॰ANR-11-LABX0030) and the Carnot Institute Polynat.

\section{References}

[1] Bourmaud A, Beaugrand J, Shah DU, Placet V, Baley C. Towards the design of high-performance plant fibre composites. Prog Mater Sci 2018;97:347-408. https://doi.org/10.1016/j.pmatsci.2018.05.005.

[2] Shah DU. Developing plant fibre composites for structural applications by optimising composite parameters: a critical review. J Mater Sci 2013;48:6083-107. https://doi.org/10.1007/s10853-0137458-7.

[3] Ramesh M, Deepa C, Kumar LR, Sanjay M, Siengchin S. Life-cycle and environmental impact assessments on processing of plant fibres and its bio-composites: A critical review. J Ind Text 2020:1528083720924730. https://doi.org/10.1177/1528083720924730.

[4] Dixit S, Goel R, Dubey A, Shivhare PR, Bhalavi T. Natural Fibre Reinforced Polymer Composite Materials - A Review. Polym Renew Resour 2017;8:71-8. https://doi.org/10.1177/204124791700800203.

[5] Müssig J, Haag K. 2 - The use of flax fibres as reinforcements in composites. In: Faruk O, Sain M, editors. Biofiber Reinf. Compos. Mater., Woodhead Publishing; 2015, p. 35-85. https://doi.org/10.1533/9781782421276.1.35.

[6] Faruk O, Sain M. Biofiber Reinforcements in Composite Materials. Elsevier; 2014.

[7] Martin N, Davies P, Baley C. Evaluation of the potential of three non-woven flax fiber reinforcements: Spunlaced, needlepunched and paper process mats. Ind Crops Prod 2016;83:194205. https://doi.org/10.1016/j.indcrop.2015.10.008.

[8] Maity S, Gon DP, Paul P. A Review of Flax Nonwovens: Manufacturing, Properties, and Applications. J Nat Fibers 2014;11:365-90. https://doi.org/10.1080/15440478.2013.861781.

[9] Omrani F, Soulat D, Ferreira M, Wang P. Effects of needle punching process and structural parameters on mechanical behavior of flax nonwovens preforms. Adv Aircr Spacecr Sci 2019;6:15768.

[10] Ouagne P, Soulat D, Evon P, Renouard S, Ferreira M, Labonne L, et al. 5 - Use of bast fibres including flax fibres for high challenge technical textile applications. Extraction, preparation and requirements for the manufacturing of composite reinforcement fabrics and for geotextiles. In: Kozłowski RM, 
Mackiewicz-Talarczyk M, editors. Handb. Nat. Fibres Second Ed., Woodhead Publishing; 2020, p. 169-204. https://doi.org/10.1016/B978-0-12-818782-1.00005-5.

[11]Composites polymères et fibres lignocellulosiques. Libr Lavoisier n.d. https://www.lavoisier.fr/livre/industries-chimiques/composites-polymeres-a-base-de-fibreslignocellulosiques/berzin/descriptif-9782746247772 (accessed April 30, 2021).

[12] Bourmaud A, Shah DU, Beaugrand J, Dhakal HN. Property changes in plant fibres during the processing of bio-based composites. Ind Crops Prod 2020;154:112705. https://doi.org/10.1016/j.indcrop.2020.112705.

[13] Ho M, Wang H, Lee J-H, Ho C, Lau K, Leng J, et al. Critical factors on manufacturing processes of natural fibre composites. Compos Part B Eng 2012;43:3549-62. https://doi.org/10.1016/j.compositesb.2011.10.001.

[14] Omrani F, Wang P, Soulat D, Ferreira M, Ouagne P. Analysis of the deformability of flax-fibre nonwoven fabrics during manufacturing. Compos Part B Eng 2017;116:471-85. https://doi.org/10.1016/j.compositesb.2016.11.003.

[15] Ouagne P, Soulat D, Moothoo J, Capelle E, Gueret S. Complex shape forming of a flax woven fabric; analysis of the tow buckling and misalignment defect. Compos Part Appl Sci Manuf 2013;51:1-10. https://doi.org/10.1016/j.compositesa.2013.03.017.

[16] Baley C, Gomina M, Breard J, Bourmaud A, Drapier S, Ferreira M, et al. Specific features of flax fibres used to manufacture composite materials. Int J Mater Form 2019;12:1023-52. https://doi.org/10.1007/s12289-018-1455-y.

[17] Binetruy C, Hilaire B, Pabiot J. Tow Impregnation Model and Void Formation Mechanisms during RTM. J Compos Mater 1998;32:223-45. https://doi.org/10.1177/002199839803200302.

[18] Kuentzer N, Simacek P, Advani SG, Walsh S. Correlation of void distribution to VARTM manufacturing techniques. Compos Part Appl Sci Manuf 2007;38:802-13. https://doi.org/10.1016/j.compositesa.2006.08.005.

[19] Bréard J, Henzel Y, Trochu F, Gauvin R. Analysis of dynamic flows through porous media. Part I: Comparison between saturated and unsaturated flows in fibrous reinforcements. Polym Compos 2003;24:391-408. https://doi.org/10.1002/pc.10038.

[20] Mehdikhani M, Gorbatikh L, Verpoest I, Lomov SV. Voids in fiber-reinforced polymer composites: A review on their formation, characteristics, and effects on mechanical performance. J Compos Mater 2019;53:1579-669. https://doi.org/10.1177/0021998318772152.

[21] Pantaloni D, Bourmaud A, Baley C, Clifford MJ, Ramage MH, Shah DU. A Review of Permeability and Flow Simulation for Liquid Composite Moulding of Plant Fibre Composites. Materials 2020;13:4811. https://doi.org/10.3390/ma13214811.

[22] Xue D, Miao M, Hu H. Permeability anisotropy of flax nonwoven mats in vacuum-assisted resin transfer molding. J Text Inst 2011;102:612-20. https://doi.org/10.1080/00405000.2010.504566.

[23] Francucci G, Rodríguez ES, Vázquez A. Study of saturated and unsaturated permeability in natural fiber fabrics. Compos Part Appl Sci Manuf 2010;41:16-21. https://doi.org/10.1016/j.compositesa.2009.07.012.

[24] May D, Aktas A, Advani SG, Berg DC, Endruweit A, Fauster E, et al. In-plane permeability characterization of engineering textiles based on radial flow experiments: A benchmark exercise. Compos Part Appl Sci Manuf 2019;121:100-14.

[25] Umer R, Bickerton S, Fernyhough A. The effect of yarn length and diameter on permeability and compaction response of flax fibre mats. Compos Part Appl Sci Manuf 2011;42:723-32. https://doi.org/10.1016/j.compositesa.2011.02.010.

[26] Francucci G, Rodríguez ES, Vázquez A. Experimental study of the compaction response of jute fabrics in liquid composite molding processes. J Compos Mater 2012;46:155-67. https://doi.org/10.1177/0021998311410484.

[27] Nguyen VH, Deléglise-Lagardère M, Park CH. Modeling of resin flow in natural fiber reinforcement for liquid composite molding processes. Compos Sci Technol 2015;113:38-45. https://doi.org/10.1016/j.compscitech.2015.03.016.

[28] Masoodi R, Pillai KM, Grahl N, Tan H. Numerical simulation of LCM mold-filling during the manufacture of natural fiber composites. J Reinf Plast Compos 2012;31:363-78. https://doi.org/10.1177/0731684412438629. 
[29] Umer R, Bickerton S, Fernyhough A. Characterising wood fibre mats as reinforcements for liquid composite moulding processes. Compos Part Appl Sci Manuf 2007;38:434-48.

[30] Lundquist L, Willi F, Leterrier Y, Mlaanson J-A. Compression behavior of pulp fiber networks. Polym Eng Sci 2004;44:45-55.

[31]Delisée C, Lux J, Malvestio J. 3D Morphology and Permeability of Highly Porous Cellulosic Fibrous Material. Transp Porous Media 2010;83:623-36. https://doi.org/10.1007/s11242-009-9464-4.

[32] Bizet L, Ouagne P, Bréard J, Baley C, Jernot J-P, Gomina M. TRANSVERSE PERMEABILITY AND KOZENY CONSTANT IN FLAX FIBER MATS PREFORMS. FPCM-9 2008 9th Int. Conf. Flow Process. Compos. Mater., 2008.

[33] Rodriguez E, Giacomelli F, Vazquez A. Permeability-porosity relationship in RTM for different fiberglass and natural reinforcements. J Compos Mater 2004;38:259-68.

[34] Kozeny J. Uber kapillare leitung der wasser in boden. R Acad Sci Vienna Proc Cl I 1927;136:271306.

[35] Carman PC. Flow of gases through porous media 1956.

[36] Schulz R, Ray N, Zech S, Rupp A, Knabner P. Beyond Kozeny-Carman: predicting the permeability in porous media. Transp Porous Media 2019;130:487-512.

[37]Chen X, Papathanasiou TD. On the variability of the Kozeny constant for saturated flow across unidirectional disordered fiber arrays. Compos Part Appl Sci Manuf 2006;37:836-46.

[38] Liu HL, Hwang WR. Permeability prediction of fibrous porous media with complex 3D architectures. Compos Part Appl Sci Manuf 2012;43:2030-8.

[39] Ozgumus T, Mobedi M, Ozkol U. Determination of Kozeny constant based on porosity and pore to throat size ratio in porous medium with rectangular rods. Eng Appl Comput Fluid Mech 2014;8:30818.

[40]Lux J, Delisée C, Thibault X. 3D CHARACTERIZATION OF WOOD BASED FIBROUS MATERIALS: AN APPLICATION. Image Anal Stereol 2006;25:25-35. https://doi.org/10.5566/ias.v25.p25-35.

[41] Joffre T, Girlanda O, Forsberg F, Sahlén F, Sjödahl M, Gamstedt EK. A 3D in-situ investigation of the deformation in compressive loading in the thickness direction of cellulose fiber mats. Cellulose 2015;22:2993-3001. https://doi.org/10.1007/s10570-015-0727-7.

[42] Viguié J, Latil P, Orgéas L, Dumont PJJ, Rolland du Roscoat S, Bloch J-F, et al. Finding fibres and their contacts within 3D images of disordered fibrous media. Compos Sci Technol 2013;89:202-10. https://doi.org/10.1016/j.compscitech.2013.09.023.

[43] Marulier C, Dumont PJJ, Orgéas L, Rolland du Roscoat S, Caillerie D. 3D analysis of paper microstructures at the scale of fibres and bonds. Cellulose 2015;22:1517-39. https://doi.org/10.1007/s10570-015-0610-6.

[44] Rolland du Roscoat S, Decain M, Thibault X, Geindreau C, Bloch J-F. Estimation of microstructural properties from synchrotron X-ray microtomography and determination of the REV in paper materials. Acta Mater 2007;55:2841-50. https://doi.org/10.1016/j.actamat.2006.11.050.

[45] Delisée C, Malvestio J, Lux J, Castéra P, Chaunier L, Chrusciel L. Microstructure et propriétés de transport de matériaux isolants à base de fibres cellulosiques. Ann. Bâtim. Trav. Publics, 2007, p. 23.

[46] Koponen A, Kandhai D, Hellén E, Alava M, Hoekstra A, Kataja M, et al. Permeability of ThreeDimensional Random Fiber Webs. Phys Rev Lett 1998;80:716-9. https://doi.org/10.1103/PhysRevLett.80.716.

[47] Caglar B, Orgéas L, Rolland du Roscoat S, Sozer EM, Michaud V. Permeability of textile fabrics with spherical inclusions. Compos Part Appl Sci Manuf 2017;99:1-14. https://doi.org/10.1016/j.compositesa.2017.03.031.

[48] Soltani P, Johari MS, Zarrebini M. Tomography-based determination of transverse permeability in fibrous porous media. J Ind Text 2015;44:738-56. https://doi.org/10.1177/1528083713512357.

[49] Soltani P, Johari MS, Zarrebini M. Effect of 3D fiber orientation on permeability of realistic fibrous porous networks. Powder Technol 2014;254:44-56. https://doi.org/10.1016/j.powtec.2014.01.001.

[50] Soltani P, Zarrebini M, Laghaei R, Hassanpour A. Prediction of permeability of realistic and virtual layered nonwovens using combined application of X-ray $\mu \mathrm{CT}$ and computer simulation. Chem Eng Res Des 2017;124:299-312. https://doi.org/10.1016/j.cherd.2017.06.035. 
[51] Hamdi SE, Delisée C, Malvestio J, Da Silva N, Le Duc A, Beaugrand J. X-ray computed microtomography and 2D image analysis for morphological characterization of short lignocellulosic fibers raw materials: a benchmark survey. Compos Part Appl Sci Manuf 2015;76:1-9.

[52] Ali MA, Umer R, Khan KA, Cantwell WJ. Application of X-ray computed tomography for the virtual permeability prediction of fiber reinforcements for liquid composite molding processes: A review. Compos Sci Technol 2019;184:107828.

[53] Loix F, Badel P, Orgéas L, Geindreau C, Boisse P. Woven fabric permeability: From textile deformation to fluid flow mesoscale simulations. Compos Sci Technol 2008;68:1624-30. https://doi.org/10.1016/j.compscitech.2008.02.027.

[54] Laurencin T, Orgéas L, Dumont PJJ, Rolland du Roscoat S, Laure P, Le Corre S, et al. 3D real-time and in situ characterisation of fibre kinematics in dilute non-Newtonian fibre suspensions during confined and lubricated compression flow. Compos Sci Technol 2016;134:258-66. https://doi.org/10.1016/j.compscitech.2016.09.004.

[55] Sentis DF, Orgéas L, Dumont PJ, Du Roscoat SR, Sager M, Latil P. 3D in situ observations of the compressibility and pore transport in Sheet Moulding Compounds during the early stages of compression moulding. Compos Part Appl Sci Manuf 2017;92:51-61.

[56] Gnaba I, Wang P, Soulat D, Omrani F, Ferreira M, Vroman P. Investigation about the Effect of Manufacturing Parameters on the Mechanical Behaviour of Natural Fibre Nonwovens Reinforced Thermoplastic Composites. Materials 2019;12:2560. https://doi.org/10.3390/ma12162560.

[57] Gnaba I, Omrani F, Wang P, Soulat D, Ferreira M, Vroman P, et al. Mechanical behavior of flax/polypropylene commingled nonwoven at dry scale: Influence of process parameters. Text Res J 2019;89:791-800. https://doi.org/10.1177/0040517518755789.

[58] Latil P, Orgéas L, Geindreau C, Dumont PJJ, Rolland du Roscoat S. Towards the 3D in situ characterisation of deformation micro-mechanisms within a compressed bundle of fibres. Compos Sci Technol 2011;71:480-8. https://doi.org/10.1016/j.compscitech.2010.12.023.

[59] Martoïa F, Cochereau T, Dumont PJJ, Orgéas L, Terrien M, Belgacem MN. Cellulose nanofibril foams: Links between ice-templating conditions, microstructures and mechanical properties. Mater Des 2016;104:376-91. https://doi.org/10.1016/j.matdes.2016.04.088.

[60] Beltran MA, Paganin DM, Uesugi K, Kitchen MJ. 2D and 3D X-ray phase retrieval of multi-material objects using a single defocus distance. Opt Express 2010;18:6423-36. https://doi.org/10.1364/OE.18.006423.

[61] Paganin D, Mayo SC, Gureyev TE, Miller PR, Wilkins SW. Simultaneous phase and amplitude extraction from a single defocused image of a homogeneous object. J Microsc 2002;206:33-40. https://doi.org/10.1046/j.1365-2818.2002.01010.x.

[62] Schneider CA, Rasband WS, Eliceiri KW. NIH Image to ImageJ: 25 years of image analysis. Nat Methods 2012;9:671-5. https://doi.org/10.1038/nmeth.2089.

[63] Lux J, Ahmadi A, Gobbé C, Delisée C. Macroscopic thermal properties of real fibrous materials: Volume averaging method and 3D image analysis. Int J Heat Mass Transf 2006;49:1958-73. https://doi.org/10.1016/j.ijheatmasstransfer.2005.09.038.

[64] Gurunathan T, Mohanty S, Nayak SK. A review of the recent developments in biocomposites based on natural fibres and their application perspectives. Compos Part Appl Sci Manuf 2015;77:1-25. https://doi.org/10.1016/j.compositesa.2015.06.007.

[65] Serra J. Image analysis and mathematical morphology. London: Academic Press. Academic press; 1982.

[66] Maire E, Colombo P, Adrien J, Babout L, Biasetto L. Characterization of the morphology of cellular ceramics by 3D image processing of X-ray tomography. J Eur Ceram Soc 2007;27:1973-81. https://doi.org/10.1016/j.jeurceramsoc.2006.05.097.

[67] Martoïa F, Orgéas L, Dumont PJJ, Bloch J-F, Flin F, Viguié J. Crumpled paper sheets: Low-cost biobased cellular materials for structural applications. Mater Des 2017;136:150-64. https://doi.org/10.1016/j.matdes.2017.09.031.

[68] Boulos V, Fristot V, Houzet D, Salvo L, Lhuissier P. Investigating performance variations of an optimized GPU-ported granulometry algorithm. Proc. 2012 Conf. Des. Archit. Signal Image Process., IEEE; 2012, p. 1-6. 
[69] Underwood EE. Stereology, or the quantitative evaluation of microstructures. J Microsc 1969;89:16180. https://doi.org/10.1111/j.1365-2818.1969.tb00663.x.

[70] Saltykov SA. Stereometric metallography. Metallurgizdat, Moscow. 1958.

[71] Roque WL, Costa RRA. A plugin for computing the pore/grain network tortuosity of a porous medium from 2D/3D MicroCT image. Appl Comput Geosci 2020;5:100019. https://doi.org/10.1016/j.acags.2020.100019.

[72] Auriault JL. Heterogeneous medium. Is an equivalent macroscopic description possible? Int J Eng Sci 1991;29:785-95. https://doi.org/10.1016/0020-7225(91)90001-J.

[73] Boutin C. Study of permeability by periodic and self-consistent homogenisation. Eur J Mech - ASolids 2000;19:603-32. https://doi.org/10.1016/S0997-7538(00)00174-1.

[74] Idris Z, Orgéas L, Geindreau C, Bloch J-F, Auriault J-L. Microstructural effects on the flow law of power-law fluids through fibrous media. Model Simul Mater Sci Eng 2004;12:995-1015. https://doi.org/10.1088/0965-0393/12/5/016.

[75] Rolland du Roscoat S, Decain M, Geindreau C, Thibault X, Bloch J-F. Microstructural Analysis of Paper Using Synchrotron X-ray Microtomography: Numerical Estimation of the Permeability and Effective Thermal Conductivity. Appita Technol Innov Manuf Environ 2008.

[76] Chalencon F, Dumont PJJ, Orgéas L, Foray G, Cavaillé J-Y, Maire E. Homogeneous and heterogeneous rheology and flow-induced microstructures of a fresh fiber-reinforced mortar. Cem Concr Res 2016;82:130-41. https://doi.org/10.1016/j.cemconres.2015.12.012.

[77] Jeulin D. Morphology and effective properties of multi-scale random sets: a review. Comptes Rendus Mécanique 2012;340:219-29.

[78]Decain M. Contribution à l'étude des relations microstructures: propriétés thermiques et d'écoulement pour les matériaux fibreux cellulosiques. PhD Thesis. Grenoble INPG, 2009.

[79] Marulier C. Etudes multi-échelles des couplages entre les propriétés hygroélastiques des papiers et leur microstructure. PhD Thesis. Grenoble, 2013.

[80] Robitaille F, Gauvin R. Compaction of textile reinforcements for composites manufacturing. III: Reorganization of the fiber network. Polym Compos 1999;20:48-61. https://doi.org/10.1002/pc.10334.

[81] Abdul Ghafour T, Colmars J, Boisse P. The importance of taking into account behavior irreversibilities when simulating the forming of textile composite reinforcements. Compos Part Appl Sci Manuf 2019;127:105641. https://doi.org/10.1016/j.compositesa.2019.105641.

[82] Baley C, Bourmaud A. Average tensile properties of French elementary flax fibers. Mater Lett 2014;122:159-61. https://doi.org/10.1016/j.matlet.2014.02.030.

[83] Bourmaud A, Morvan C, Bouali A, Placet V, Perré P, Baley C. Relationships between micro-fibrillar angle, mechanical properties and biochemical composition of flax fibers. Ind Crops Prod 2013;44:343-51. https://doi.org/10.1016/j.indcrop.2012.11.031.

[84] Rolland du Roscoat S, Decain M, Thibault X, Geindreau C, Bloch J-F. Estimation of microstructural properties from synchrotron X-ray microtomography and determination of the REV in paper materials. Acta Mater 2007;55:2841-50. https://doi.org/10.1016/j.actamat.2006.11.050.

[85] Peyrega C, Jeulin D. Estimation of tortuosity and reconstruction of geodesic paths in 3D. Image Anal Stereol 2013;32:27-43.

[86] Soltani P, Zarrebini M, Laghaei R, Hassanpour A. Prediction of permeability of realistic and virtual layered nonwovens using combined application of X-ray $\mu \mathrm{CT}$ and computer simulation. Chem Eng Res Des 2017;124:299-312. https://doi.org/10.1016/j.cherd.2017.06.035. 
The authors declare no conflict of interest.

\section{Iterest Statement \\ confict of Interest Statement}

The authors declare no conflict of interest.

The authors declare no conflict of interest.

\section{the}

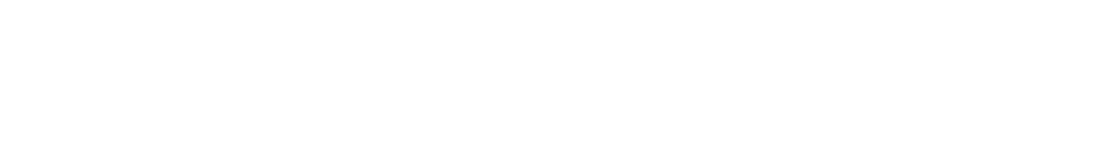

